\title{
SELF-HARM INVENTORY (SHI) VERSI INDONESIA SEBAGAI INSTRUMEN DETEKSI DINI PERILAKU SELF-HARM
}

\author{
Kusumadewi $\mathrm{AF}^{*}$, Yoga $\mathrm{BH}^{*}$, Sumarni*, Ismanto $\mathrm{SH}^{*}$ \\ * Departemen Ilmu Kedokteran Jiwa FKKMK UGM Yogyakarta
}

\begin{abstract}
ABSTRAK
Latar Belakang: Perilaku menyakiti diri sendiri (self-harm) merupakan fenomena gunung es yang umum terjadi pada populasi normal maupun pada pasien yang terdiagnosis klinis memiliki gangguan jiwa. Perilaku ini memiliki tren yang meningkat dan dapat berkembang menjadi tindakan bunuh diri apabila tidak ditangani dengan tepat. Upaya deteksi dini dan pencegahan perilaku self-harm penting untuk mencegah kematian dini akibat bunuh diri. Saat ini belum ada instrumen skrining perilaku menyakiti diri dalam bahasa Indonesia.
\end{abstract}

Tujuan: Melakukan uji validitas dan reliabilitas kuesioner self-harm versi Indonesia.

Metode: Penelitian ini mer upakan studi deskriptif dengan rancangan potong lintang. Subjek penelitian ini adalah 110 pasien poli jiwa RSUD Bantul Yogyakarta. Perilaku self-harm diukur menggunakan instrumen Self-harm Inventory (SHI) versi Indonesia. Uji validasi menggunakan Index Validitas Aiken (IVA), menggunakan Pearson Product Moment, dan uji reliabilitas menggunakan Cronbach's Alpha.

Hasil: Didapatkan 110 responden yang terdiri atas 57 laki-laki $(51,8 \%)$ dan 53 perempuan $(48,2 \%)$. Pada uji validitas isi instrumen didapatkan hasil yang baik (Indeks Validitas Aiken berkisar 0,83-0,97). Uji validitas konstrak menggunakan korelasi Pearson menghasilkan 21 item valid $(r>0,25)$

Kesimpulan: Self-Harm Inventory versi Indonesia valid dan reliabel untuk deteksi dini perilaku self-harm dalam setting klinis

Kata Kunci: Reliabilitas, self harm inventory, validitas

Corresponding author : Andrian Fajar Kusumadewi Departemen Ilmu Kedokteran Jiwa FKKMK UGM/RSUP dr.Sardjito Yogyakarta (0274) 587333 psw.554 | email: andrian.fajar.k@ugm.ac.id 


\section{LATAR BELAKANG}

Perilaku menyakiti diri sendiri (self-harm) didefinisikan sebagai perilaku seseorang untuk melukai diri sendiri dengan berbagai cara tanpa memandang ada atau tidaknya niat dan keinginan untuk mati (NICE, 2015; WHO, 2015). Perilaku ini merupakan sebuah fenomena penting dalam bidang kesehatan jiwa yang dapat terjadi baik pada populasi normal maupun pasien dengan diagnosis gangguan jiwa. Beberapa gangguan jiwa yang terkait erat dengan perilaku self-harm yaitu gangguan kepribadian ambang (Borderline personality disorder), gangguan depresi, gangguan bipolar, dan skizofrenia (Sadock, BJ.\& Sadock, V., 2009). Perilaku self-harm sendiri sebenarnya bukanlah sebuah gangguan jiwa, namun merupakan kegagalan seseorang dalam melakukan coping dalam menghadapi stress (Carroll, et al., 2014). Meski tidak semua orang dengan perilaku self-harm akan selalu berlanjut menjadi bunuh diri, namun orang dengan perilaku ini memiliki resi- ko 1.68 kali lipat untuk melakukan bunuh diri (Chan M.,et al 2016). Apabila metode self-harm yang dilakukan menimbulkan luka serius atau disertai dengan pikiran bunuh diri yang muncul secara intensif, maka selfharm dapat berakibat pada kematian (Sansone, et al., 1998).

Tingginya jumlah kejadian bunuh diri dengan minimnya studi tentang perilaku self-harm di Indonesia menjadi tantangan bagi klinisi untuk menekan jumlah ini. Salah satu upaya yang dapat dilakukan yaitu dengan mengembangkan instrumen deteksi dini terhadap perilaku self-harm dalam setting klinis. Instrumen tersebut haruslah mudah digunakan, singkat, serta memiliki tingkat reliablitias dan validitas yang tinggi. Diharapkan instrumen tersebut dapat mencegah kejadian kematian dini akibat bunuh diri (National Institute for Health and Care Excellence, 2015).

Instrumen Self-harm Inventory (SHI) pertama kali dikembangkan di Amerika Serikat oleh Randy Sansone et al. pada tahun 2011 dalam bahasa Inggris. Instrumen ini memiliki beberapa kelebihan dalam menilai aspek-aspek perilaku self-harm. Instrumen ini terdiri dari 22 item yang cukup singkat sehingga sesuai untuk menjaring populasi dalam jumlah banyak. Diperlukan uji validasi instrumen SHI versi Indonesia yang setara dengan SHI versi asli agar instrumen ini dapat dipahami dalam bahasa Indonesia namun tetap relevan dalam mengukur perilaku self-harm sebagaimana fungsi semestinya.

\section{METODE}

Penelitian ini merupakan studi deskriptif dengan rancangan potong lintang. Pengambilan data dilakukan pada bulan April dan Mei tahun 2017 dengan metode consecutive sampling. Studi ini melibatkan pasien poli jiwa RSUD Bantul dengan karakteristik usia >17 tahun serta telah didiagnosis dengan gangguan jiwa. Studi ini mengeksklusikan pasien dengan gangguan jiwa organic, gangguan spektrum autisme, retardasi mental, dan demensia.

Instrumen yang digunakan dalam penelitian ini adalah Self-harm Inventory (SHI) versi Indonesia yang bertujuan menilai perilaku self harm. Instrumen ini terdiri atas 22 item pernyataan ordinal yang diisi sendiri dengan jawaban ya (skor 1) dan tidak (skor 0). Instrumen ini menghasilkan rentang skor 0-22. Instrumen SHI versi Indonesia diperoleh melalui proses penerjemahan bahasa yang dilakukan dalam 6 langkah: terjemahan awal, terjemahan sintesis, terjemahan balik, penilaian komite, pre-testing, dan pembahasan hasil akhir keterbacaan terjemahan kepada komite ahli yang terdiri dari dua orang psikiater dan seorang psikolog untuk menghasilkan instrumen SHI yang siap diujikan pada responden.

Pada studi ini dilakukan analisis hasil menggunakan validitas internal yang terdiri atas 1.) Uji validitas isi tiap item instrumen yang dinilai menggunakan rumus Aiken $\mathrm{V}$ berdasarkan penilaian komite ahli dengan nilai 1-5 (tidak relevan - relevan) dan 2.) Uji validitas konstrak yang menguji setiap item menggunakan uji korelasi Pearson Product Moment dengan batas minimal untuk koefisien korelasi pada analisis item ditetapkan 0,25; dan Analisis faktor, yaitu exploratory factor analysis (EFA) dan confirmatory factor analysis (CFA) dengan mempertimbangkan nilai Keiser-Meyers-Oklin (KMO) > 0,6; Barlett test of Sphericity ( $\mathrm{p}<0,05)$. Uji reliablitias konsistensi internal dilakukan dengan menghitung koefisien alfa Cronbach. Hasil dapat diterima apabila nilai koefisien Cronbach $>0,7$. Data dikoding dan dianalisis secara statistic menggunakan SPSS versi 17. Nilai signifikan ditetapkan $\mathrm{p}<0,05$.

\section{HASIL}

Karakteristik Demografis Responden

Total diperoleh 110 responden yang terdiri atas 53 perempuan (48.2\%) dan 57 laki-laki (51.8\%). Karakteristik demografis responden dicantumkan pada tabel 1.

\section{$\underline{\text { Uji Validitas Isi }}$}

Telah dilakukan proses penerjemahan instrumen Selfharm Inventory dari bahasa aslinya (Inggris) ke dalam bahasa Indonesia. Penerjemahan dilakukan oleh penerjemah professional dengan latar belakang pendidikan bahasa Inggris dari Akademi Bahasa Asing LPI Jakarta Pusat. Hasil terjemahan kemudian didiskusikan dengan 
komite ahli yang terdiri atas dua psikiater dan seorang psikolog, dan uji keterbacaan dilakukan kepada dua sampel populasi 1.) Pasien poli jiwa RSUD Bantul yang tidak memiliki diagnosis gangguan jiwa, dan 2.) Mahasiswa program sarjana pendidikan dokter dan pndidikan dokter spesialis kedokteran jiwa FKKMK UGM Yogyakarta. Lebih dari $80 \%$ total responden menyatakan instrumen dapat dipahami dengan cukup jelas.

\section{Gambar 1. Alur Penelitian}

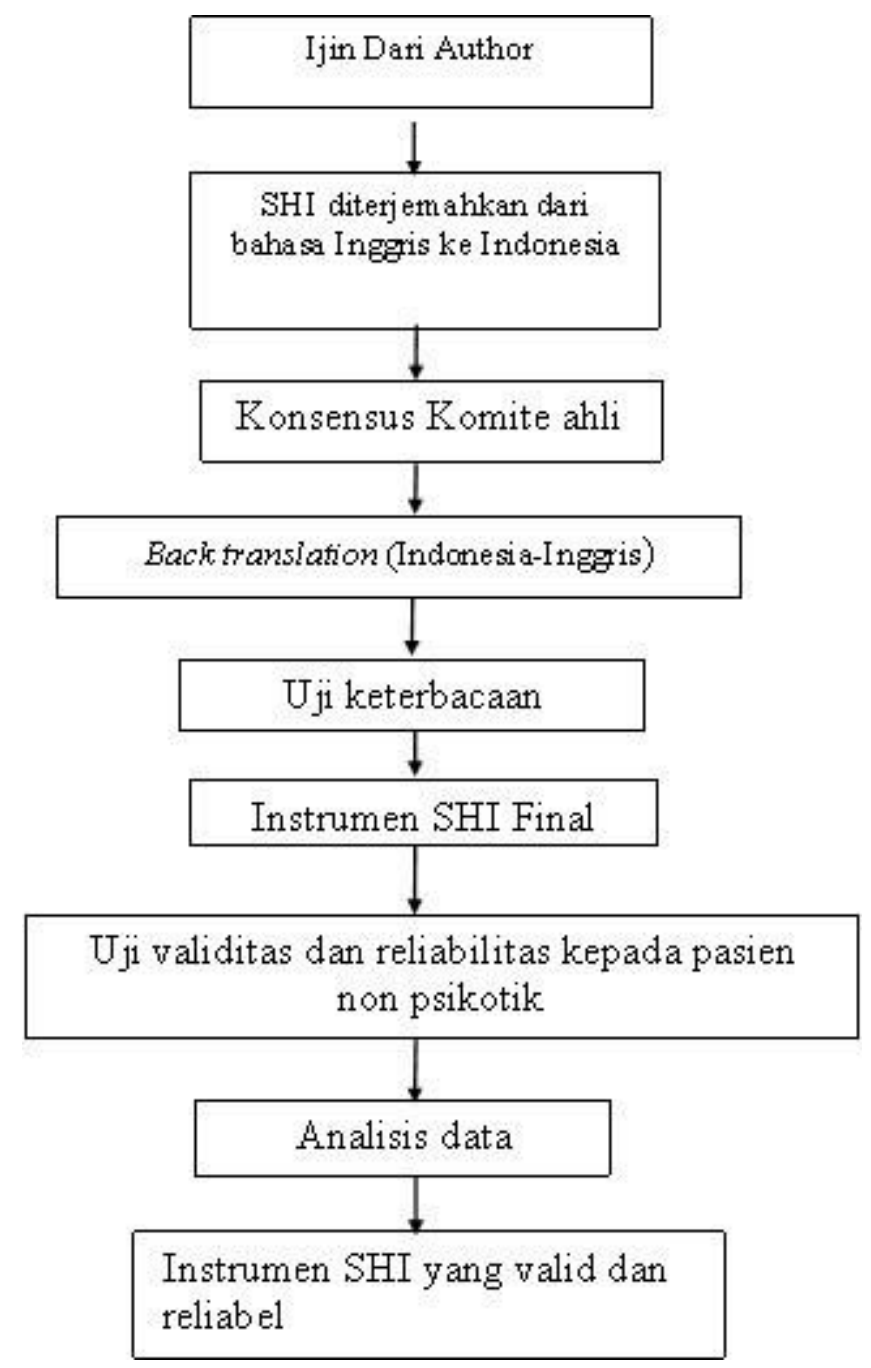

Kemudian hasil uji keterbacaan didiskusikan kembali oleh komite ahli dan peneliti sehingga dihasilkan versi akhir dari kuesioner Self-harm Inventory (SHI) hasil consensus ahli pada tabel 2 .

Selanjutnya, dilakukan perhitungan validitas isi tiap item berdasarkan penilaian oleh tiga komite ahli yang terdiri dari dua psikiater senior dan seorang psikolog dengan skor penilaian 1-5 (1: Tidak relevan; 2: Kurang relevan; 3: Agak relevan; 4: Relevan; 5: Sangat relevan). Pada skor total dari ketiga penilai kemudian dilakukan perhitungan koefisien validitas isi menggunakan indeks validitas Aiken's.

Berdasarkan tabel 3 didapatkan nilai berkisar antara 0,83
-0,97 Hal ini menunjukkan bahwa keduapuluh dua item memiliki validitas isi yang baik.

Selanjutnya dilakukan analisis item dengan uji korelasi Pearson Product Moment untuk menghitung korelasi item-total yang menunjukkan kesesuaian antara fungsi item dengan fungsi tes secara keseluruhan. Dengan kata lain item tersebut mengukur hal yang sama dengan apa yang diukur oleh tes sebagai keseluruhan. Pengujian kesesuaian fungsi item dengan fungsi ukur tes dilakukan dengan menghitung koefisien korelasi antara distribusi skor pada setiap item dengan distribusi skor total tes itu sendiri. Batasan minimal koefisien korelasi pada analisis item adalah 0,30. Semakin tinggi koefisien korelasinya, berarti semakin berkualitas item tersebut. Pada tabel 4 dapat dilihat bahwa korelasi item-total terbesar adalah item no 2 yaitu 0,690, sedangkan yang terkecil adalah item no 22 sebesar 0,173 dengan nilai p 0,071 sehingga item nomor 22 tidak valid.

\section{Tabel 1. Karakteristik Demografis}

\begin{tabular}{llll}
\hline Variabel & & N & $\mathbf{( \% )}$ \\
\hline Jenis & Laki-laki & 57 & 51,8 \\
Kelamin & Perempuan & 53 & 48,2 \\
& & & \\
Umur & $<$ 30 Tahun & 36 & 32,7 \\
& $\geq 30$ Tahun & 74 & 67,3 \\
& & & \\
Pekerjaan & Bekerja & 54 & 49,1 \\
& Tidak Bekerja & 56 & 50,9 \\
Pendidikan & $<$ SMA & & \\
& $>$ SMA & 97 & 88,2 \\
Status & Menikah & 25 & 10,9 \\
Pernikahan & Belum/Cerai/Duda & 85 & 77,3 \\
& & & \\
Gangguan & Depresi & 35 & 31,8 \\
Jiwa & Cemas & 19 & 17,3 \\
& Skizofrenia & 56 & 50,9 \\
& & & \\
Perilaku & Skor SHI > 5 & 24 & 21,8 \\
Self Harm & Skor SHI < 5 & 86 & 78,2 \\
\hline
\end{tabular}

Selanjutnya untuk melakukan uji validasi konstruk pada penlitian ini dilakukan analisis faktor yaitu pertama, exploratory factor analysis (EFA) untuk mengidentifikasi berbagai faktor yang membentuk suatu konstrak dengan cara menemukan varians skor terbesar dengan jumlah faktor yang paling sedikit. Dilakukan juga confirmatory factor analysis (CFA) untuk mengkonfirmasi apakah itemitem perrnyataan telah sesuai dengan komponen (faktor). Penelitian ini memenuhi syarat untuk analisis faktor karena 1.) Memenuhi minimal jumlah sampel 100 yang dimana pada penelitian ini adalah $110 ;$ 2.) Telah dihasilkan nilai 
Keizer Meyers Oklin (KMO) 0,686 (>0.6) yang menunjukkan jumlah sampel telah mencukupi; 3.) Barlett test of Sphericity menunjukkan tingkat kemaknaan dengan nilai 0,000 ( $\mathrm{p}<0,05)$, menunjukkan bahwa data dapat diprediksi dan dianalisis lebih lanjut. Sehingga dari proses ekstraksi didapatkan 8 faktor yang dapat dilihat pada tabel 5.

Tabel 2. Kuesioner Self-harm Inventory (SHI) Hasil Konsensus Ahli

Asli (A): Have you ever intentionally or on purpose?

Terjemahan (T): Pernahkah Anda dengan sengaja:

1. A: Overdose

T: Overdosis

2. A: Cut yourself on purpose

$\mathrm{T}$ : Mengiris dirimu sendiri dengan sengaja

3. A: Burned yourself on purpose

$\mathrm{T}$ : Membakar dirimu sendiri dengan sengaja

4. A: Hit yourself

$\mathrm{T}$ : Memukul diri sendiri

5. A: Banged your head on purpose

$\mathrm{T}$ : Membenturkan kepalamu dengan sengaja

6. A: Abuse alcohol

T: Menjadi peminum alkohol

7. A: Driven recklessly on purpose

$\mathrm{T}$ : Menyetir secara ceroboh dengan sengaja

8. A: Scratched yourself on purpose

T: Mencakar dirimu sendiri dengan sengaja

9. A: Prevented wound from healing

T: Tidak mengobati lukamu

10. A: Made medical situation worse on purpose e.g skipped medication

$\mathrm{T}$ : Membuat kondisi penyakit medis memburuk dengan sengaja, contohnya tidak menuruti anjuran pengobatan

11. A: Been promiscuous i.e had many sexual partners (if yes how many) T: Tidak memilih-milih bersetubuh deng an siapa saja, contohnya punya banyak pasangan seksual (jika iya berapa banyak)

12. A: Set yourself up in relationship to be rejected

$\mathrm{T}$ : Memposisikan dirimu dalam hubungan yang ditolak

13. A: Abused prescription medication $\mathrm{T}$ :Menyalahgunakan resep peng obatan

14. A: Distanced yourself from God as punishment

T: Menjauhkan diri dari Tuhan sebagai hukuman

15. A: Engaged in emotionally abusive relationships (if yes number relationship

$\mathrm{T}$ : Terlibat hubungan yang menyiksa pasangannya secara emosional/psikis (jika iya berapa kali pernah melakukannya)

16. A: Engaged in sexually abusive relationship (if yes, number of relationship)

T: Terlibat hubungan yang menyiksa pasangan secara seksual (jika iya berapa kali pernah melakukannya)

17. A: Lose job on purpose

$\mathrm{T}$ : Keluar dari pekerjaan dengan sengaja

18. A: Attempted suicide

T: Melakukan percobaan bunuh diri

19. A: Exercised an injury on purpose

$\mathrm{T}$ : Membuat diri terluka dengan sengaja

20. A: Tortured yourself with self defeating thoughts

$\mathrm{T}$ : Menyiksa diri dengan pemikiran yang mengalahkan diri sendiri (tidak memihak diri sendiri)

21. A: Starved yourself to hurt yourself

T: Membuat diri kelaparan untuk menyakiti diri sendiri

22. A: Abuse laxatives to hurt yourself

T: Memaksakan mengkonsumsi obat pencahar/ obat cuci perut untuk menyakiti diri sendiri
Uji Reliabilitas

Hasil uji reliabilitas konsistensi internal instrumen SHI versi Indonesia didapatkan nilai Cronbach's alpha 0,831. Oleh karena nilai Cronbach's alpha $\geq 0,70$, maka dapat disimpulkan instrumen SHI versi Indonesia reliabel.

\section{Tabel 3. Penilaian Validitas Isi berdasarkan Indeks Validitas Aiken's}

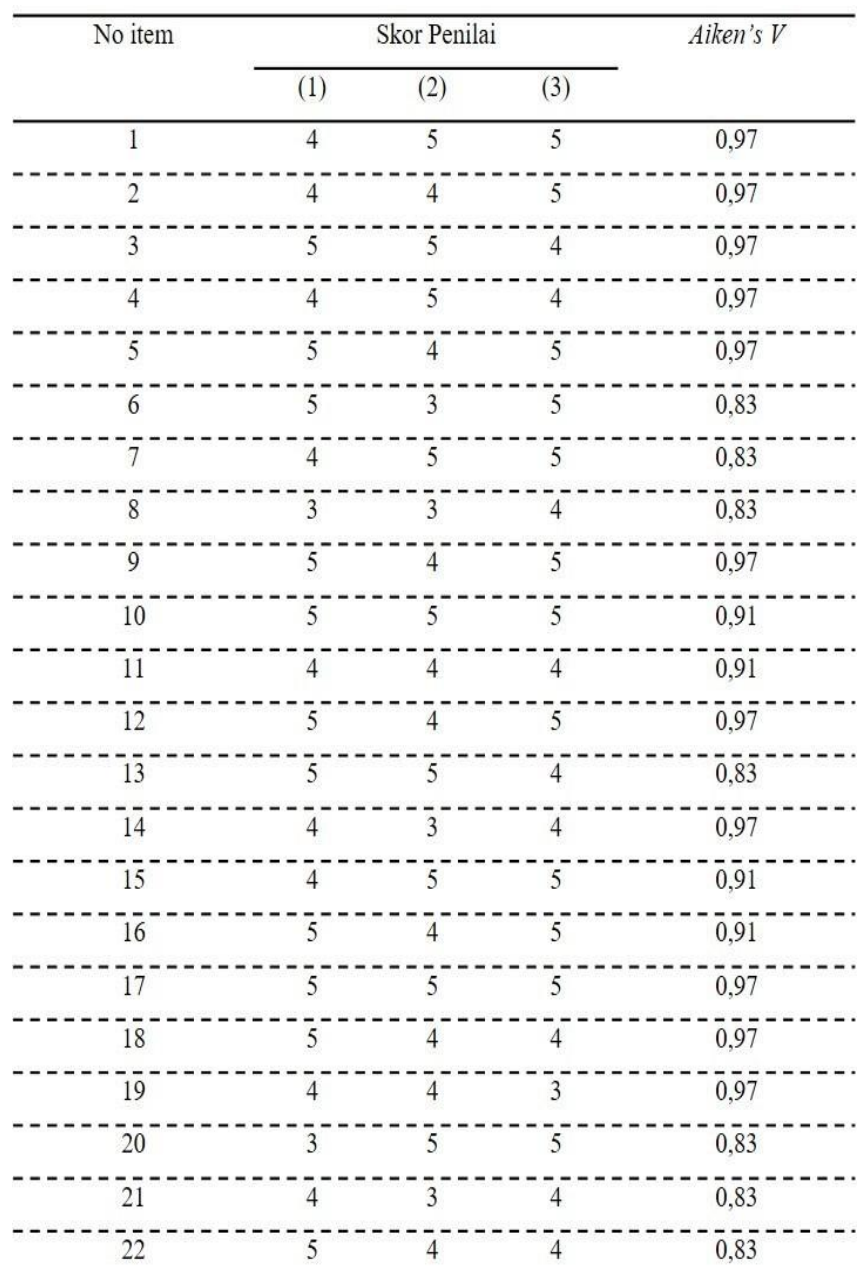

\section{PEMBAHASAN}

\section{Perilaku self-harm}

Pada penelitian ini, metode menyakiti diri yang terbanyak dilakukan oleh responden wanita adalah mengiris/ menyayat kulit, memperburuk kondisi medis dengan tidak mematuhi anjuran pengobatan, serta pikiran menyalahkan diri sendiri, sedangkan untuk responden lakilaki paling banyak memukul diri, membentur-benturkan kepala, menyetir dengan ceroboh serta keluar dari pekerjaan dengan sengaja. Pada kedua jenis kelamin ditemukan adanya kesa- maan jenis periaku ide bunuh diri, overdosis serta menjauhi Tuhan dengan cara tidak beribadah. Perbedaan dan persamaan jenis perilaku selfharm pada kedua jenis kelamin ini sesuai dengan penelitian Andover, et al., 2010. Selain itu menurut Tang, et al.,2016 yang mendapatkan bentuk self-harm yang paling umum adalah melukai kulit dengan silet 
atau berbagai macam benda tajam. Namun selain itu, self harm juga muncul dalam bentuk membakar tubuh, memukul diri, mengorek bekas luka, menjambak rambut, hingga menelan zat-zat beracun (Tang, et al.,2016).

\section{Tabel 4. Hasil Uji Korelasi Pearson Product Moment Setiap Item dengan Skor Total dalam Instrumen SHI}

\begin{tabular}{lll|lll}
\hline $\begin{array}{l}\text { No } \\
\text { tem }\end{array}$ & $\begin{array}{l}\text { Pearson } \\
\text { Correlation }\end{array}$ & $\begin{array}{l}\text { Sig. } \\
\text { (2-tailed }\end{array}$ & $\begin{array}{l}\text { No } \\
\text { item }\end{array}$ & $\begin{array}{l}\text { Pearson } \\
\text { Correlation }\end{array}$ & $\begin{array}{l}\text { Sig. } \\
\text { (2-Tailed) }\end{array}$ \\
\hline & 0,289 & 0,001 & 12 & 0,432 & 0,000 \\
\hdashline & 0,690 & 0,001 & 13 & 0,321 & 0,000 \\
\hdashline & 0,450 & 0,001 & 14 & 0,356 & 0,000 \\
\hline 5 & 0,666 & 0,001 & 15 & 0,484 & 0,000 \\
\hline 5 & 0,511 & 0,001 & 16 & 0,312 & 0,001 \\
\hline 5 & 0,352 & 0,001 & 17 & 0,571 & 0,000 \\
\hline 7 & 0,476 & 0,002 & 18 & 0,594 & 0,000 \\
\hline 3 & 0,456 & 0,000 & 19 & 0,602 & 0,000 \\
\hdashline 7 & 0,539 & 0,000 & 20 & 0,556 & 0,000 \\
\hline 10 & 0,467 & 0,000 & 21 & 0,562 & 0,000 \\
\hline 11 & 0,415 & 0,000 & 22 & 0,173 & 0,071 \\
\hline
\end{tabular}

\section{Instrumen Self-harm Inventory (SHI)}

Secara umum, item kuesioner Self-harm Inventory (SHI) diklasifikasikan menjadi beberapa kelompok pertanyaan yaitu: 1.) Perilaku menyakiti diri sendiri secara langsung (direct) yang terdiri atas ringan (item nomor 2, 4, $6,8,19)$ dan berat (item nomor 1, 3, 5, 18); 2.) Perilaku menyakiti diri sendiri secara tidak langsung (item nomor 9 , 10, 14, 21); 3.) Perilaku berisiko (item nomor 7, 11, 13, 15, 16, 22); dan kognisi (item nomor 12, 17, 20) (Sansone, 1998)

Berdasarkan hasil analisis statistik pada studi ini didapatkan item nomor 22 tidak valid. Hal ini dikarenakan oleh minimnya jumlah sampel yang memilih item nomor 22 dan berakibat pada kurangnya jumlah variasi yang dibutuhkan untuk estimasi statistik yang reliabel terhadap fungsi item ini. Hal ini juga didapatkan pada studi penggunaan SHI versi terjemahan bahasa Jerman oleh Müller et al., pada tahun 2016 dengan analisis studi yang menunjukkan hasil tidak valid pada item nomor 21 dan 22 (Müller, 2016). Namun fungsi dari item ini sudah dapat terwakili oleh 5 item lainnya yang menggambarkan pertanyaan terkait adanya perilaku berisiko sehingga masih bisa dipakai di dalam instrumen versi Indonesia.

Studi oleh Latimer et al., 2009 melaporkan pengujian validitas instrumen Self-harm Inventory (SHI) pada populasi non-klinis menunjukkan tidak adanya perbedaan komponen psikometris yang bermakna jika dibandingkan dengan penggunaan SHI pada populasi klinis. Studi ini juga mengemukakan skor cut-off $>5$ cukup valid untuk menyatakan adanya perilaku self-harm ringan, sementara skor cut-off > 11 menyatakan adanya kecenderungan psikopatologi dan perlu dilakukan pemeriksaan psikiatri yang lebih mendalam. Sehingga instrumen SHI dapat menjadi alat deteksi dini perilaku selfharm yang handal baik untuk populasi klinis maupun nonklinis, maupun sebagai alat deteksi dini perilaku psikopatologi dengan perilaku self-harm sebagai salah satu gejala psikopatologi lainnya.

\section{Tabel 5. Ekstraksi Faktor}

\begin{tabular}{|c|c|c|c|c|c|c|c|c|}
\hline \multicolumn{9}{|c|}{ Related Component Matrix } \\
\hline \multicolumn{9}{|c|}{ Component } \\
\hline & 1 & 2 & 3 & 4 & 5 & 6 & 7 & 8 \\
\hline 1 & & & & & & & & 0,895 \\
\hline 2 & & & & & 0,460 & & & \\
\hline 3 & & & 0,587 & & & & & \\
\hline \multirow[t]{2}{*}{4} & 0,6 & & & & & & & \\
\hline & 69 & & & & & & & \\
\hline \multirow[t]{2}{*}{5} & 0,7 & & & & & & & \\
\hline & 74 & & & & & & & \\
\hline 6 & & & & & & & 0,803 & \\
\hline 7 & & & & 0,440 & & & & \\
\hline 8 & & & & 0,686 & & & & \\
\hline \multirow[t]{3}{*}{9} & & & & & & 0 & 0,419 & \\
\hline & & & & & & 63 & & \\
\hline & & & & & & 8 & & \\
\hline 10 & & & & 0,710 & & & & \\
\hline 11 & & 0,741 & & & & & & \\
\hline 12 & & & 0,804 & & & & & \\
\hline 13 & & 0,785 & & & & & & \\
\hline \multirow[t]{3}{*}{14} & & & & & & 0 & & \\
\hline & & & & & & 81 & & \\
\hline & & & & & & 0 & & \\
\hline 15 & & & & & 0,843 & & & \\
\hline 16 & & 0,806 & & & & & & \\
\hline 17 & & & & & & & 0,496 & \\
\hline \multirow[t]{2}{*}{18} & 0,5 & & & & & & & \\
\hline & 86 & & & & & & & \\
\hline \multirow[t]{2}{*}{19} & 0,5 & & & & 0,597 & & & \\
\hline & 16 & & & & & & & \\
\hline 20 & & & 0,510 & & & & & 0,470 \\
\hline 21 & & & 0,711 & & & & & \\
\hline 22 & & & & 0,596 & & & & \\
\hline
\end{tabular}

Extraction Method: Principal Component Analysis Rotation Method: Varimax with Kaizer Normalization

\section{KESIMPULAN}

Self-harm Inventory (SHI) versi Indonesia adalah instrument yang valid dan reliable untuk menilai perilaku self-harm pada setting klinis, sehingga hanya berlaku pada populasi klinis psikiatri. 


\section{UCAPAN TERIMA KASIH}

Ucapan terima kasih kepada 1.) Kepala departemen kedokteran jiwa FKKMK UGM Dr. dr. Carla Marchira Sp.KJ (K) dan 2.) Direktur RSUD Panembahan Senopati Kabupaten Bantul atas izin terlaksananya penelitian ini; 3.) dr. Vista Nuratri, Sp.KJ selaku psikiater poliklinik jiwa RSUD Bantul; dan 4.) dr. Lisdayanti, Sp.KJ sebagai rekan yang membantu dalam pengumpulan data.

\section{PERNYATAAN KONFLIK KEPENTINGAN/ CONFLICT OF INTEREST)}

Penulis tidak memiliki konflik kepentingan dalam pelaksanaan penelitian ini.

\section{DAFTAR PUSTAKA}

Andover M, Primack J, Gibb B, Pepper C. "An Examination of Non-Suicidal Self-Injury in Men: Do Men Differ From Women in Basic NSSI Characteristics?" Archives of Suicide Research., vol. 14, pp. 79-88, 2010;

Carroll, R., Metcalfe, C. and Gunnell, D. "Hospital Presenting Self-Harm and Risk of Fatal and Non-Fatal Repetition: Systematic Review and Meta-Analysis." PLoS ONE, vol. 9, p.e89944, 2014

Chan, M., Bhatti, H., Meader, N., Stockton, S., Evans, J., O'Connor, R., Kapur, N. and Kendall, T. "Predicting suicide following self-harm: systematic review of risk factors and risk scales." British Journal of Psychiatry, vol. 209 (4), pp: 277-283, 2016

Latimer S, Covic T, Cumming S, Tennant A. "Psychometric analysis of the Self-Harm Inventory using Rasch modelling”. BMC Psychiatry. Vol. 9(1), 2009

Müller A, Claes L, Smits D, Brähler E, de Zwaan M. "Prevalence and Correlates of Self-Harm in the German General Population.” PLOS ONE. Vol. 11(6), p.e0157928, 2016

National Institute for Health and Care Excellence. "Self -harm - NICE Pathways." 2016 [online] URL: https:// pathways.nice.org.uk/pathways/self-harm [Diakses 11 Desember 2016].

Sadock, BJ.\& Sadock, V. "Kaplan \& Sadock's Comprehensive Textbook of Psychiatry." 9th ed., Philadelphia: Lippincott William \& Wilkins; 2009

Sansone, R., Wiederman, M. and Sansone, L. "The selfharm inventory (SHI): Development of a scale for identifying self-destructive behaviors and borderline personality disorder.” Journal of Clinical Psychology, vol. 54(7), pp. 973-983, 1998

Tang, J., Yang, W., Ahmed, N., Ma, Y., Liu, H., Wang,
J., Wang, P., Du, Y. and Yu, Y. "Stressful Life Events as a Predictor for Nonsuicidal Self-Injury in Southern Chinese Adolescence." Medicine, vol. 95(9), p.e2637, 2016

World Health Organization. "Assessment for Self Harm/ Suicide in Persons with Priority Mental, Neurological and Substance Use Disorders. " 2015. [online].URL: https:// www.who.int/mental_health/mhgap/evidence/suicide/q1/ en/ [Diakses 25 Desember 2016] 